\title{
Para uma arqueologia da prática escolar na educação da infância
}

\author{
Archaeology of school practice in education of children
}

\section{Per un arqueología de la práctica na escuela de la infancia}

\author{
MAGALI REIS* \\ LENISE MARIA ORTEGA** \\ JULIA CALVO ${ }^{* * *}$ \\ MARIANA VERÍSSIMO ${ }^{* * * *}$
}

\begin{abstract}
$\diamond$
RESUMO

As reflexões apresentadas neste artigo decorrem das experiências de pesquisa e extensão universitária desenvolvidas em instituições de Ensino Fundamental e Educação Infantil. A ideia de trabalhar com a Arqueologia das Práticas Escolares surgiu a partir de nossa imersão nos campos de investigação científica nas escolas, da observação e do registro de inúmeras práticas escolares, as quais, ao final do ano letivo, perdem-se, não havendo sistematização e produção de acervo do rico material produzido. Buscam-se, na arqueologia, os conceitos, e métodos de coleta de dados para se pensar as possibilidades de constituição de acervos digitais que possibilitem a análise da produção material do ensino na educação básica, delimitando o campo de indagação à "Escola de Infância" compreendida como a Educação Infantil (EI) e os anos iniciais do Ensino Fundamental (EF). E parte-se do entendimento que a articulação e as políticas de transição entre essas escolas necessitam ser repensadas continuamente.
\end{abstract}

Palavras-chave: Arqueologia. Prática escolar. Educação. Formação de professores. Cultura material.

\begin{abstract}
The reflections presented in this article flow from the research experience and extension developed in institutions of Basic School and Childhood Education Schools. The idea of working with the Archaeology of School Practice emerged from our immersion in scientific research fields in schools and the observation and recording of numerous school practices, which, at the end of the school year, ended up getting lost, there being no systematization and production of a collection of rich material studies and teacher training. We seek, in archeology, concepts, procedures and data collection methods for considering the numerous digital collections of constitution of possibilities that enable the analysis of teaching material production in basic education, limiting our field of inquiry to the "Childhood School understood as the Childhood Education Schools (EI) and the early years of Elementary School (EF), starting from the understanding that the students of these levels of education they are still children and that coordination and policy transition between these schools need to be rethought continuously.
\end{abstract}

Keywords: Archaeology. School practice. Education. Teacher education. Material culture.

\section{RESUMEN}

Las reflexiones presentadas en este artículo se originan de las experiencias de investigación y extensión universitaria desarrolladas en Instituciones de Enseñanza Primaria y Educación Infantil. La idea de trabajar con la Arqueología de las Prácticas Escolares ha surgido a partir de nuestra inmersión en los campos de investigación científica en las escuelas; de la observación y del registro de innúmeras prácticas escolares, las cuales, al final del año lectivo, se pierden, sin haber sistematización y producción de acervo del rico material producido. Buscamos, en la arqueología, los conceptos y métodos de recolección de datos para que pensemos las posibilidades de constitución de acervos digitales que nos permiten un análisis de la producción material de enseñanza en la educación infantil, delimitando nuestro campo de cuestionamientos a la "Escuela de la Infancia" comprendida como la Educación Infantil (EI) y los años iniciales de la Enseñanza Primaria (EP), partiendo del entendimiento que la articulación y las políticas de transición entre esas escuelas necesitan ser repensadas continuamente.

Palabras clave: Arqueología. La práctica escolar. Educación. La formación del profesorado. Cultura material.

* Doutora e Pós Doutora em Educação, na área de concentração: Sociedade e Cultura, pela Universidade Estadual de Campinas. Atualmente é Professora Adjunta do Programa de Pós-Graduação Stricto Sensu em Educação da PUC Minas. E-mail: <magali_reis@pucminas.br>.

** Mestre em Educação pela Pontifícia Universidade Católica de Campinas. Possui Estudos Avançados (primeira etapa do doutorado) em Ciências da Educação pela Universidad de Extremadura.E-mail: <lenisemro@gmail.com>.

*** Doutora em Ciências Socias pela PUC Minas. Atualmente é professora adjunta IV da PUC Minas e pesquisadora do Instituto Histórico Israelita Mineiro. E-mail: <juliacalvo1@gmail.com>.

**** Doutora em Filosofia pela Université d'Aix-MarseilleI-França e Doutora em Educação: Conhecimento e Inclusão Social, pela Faculdade de Educação da UFMG. Professora Adjunto IV (PUC Minas).E-mail: <mverissimo@pucminas.br>. 


\section{EM FAVOR DE UMA ARQUEOLOGIA DA PRÁTICA ESCOLAR}

Este artigo foi concebido a partir da convergência de ideias e concepções teórico-metodológicas de um grupo de estudiosas dedicadas às questões colocadas pelas práticas escolares cotidianas nas escolas de infância. As reflexões apresentadas decorrem das experiências de pesquisa e extensão universitária, desenvolvidas em instituições de Ensino Fundamental e de Educação Infantil, das observações, dos registros e das análises dessas investigações científicas, bem como da formação de profissionais em exercício, nos grupos de formação continuada e na docência no Ensino Superior.

Como resultado desses estudos, constatam-se as dificuldades das escolas de infância de preservarem sua produção material, bem como as expectativas dos profissionais de educação quanto ao registro e ao tratamento a ser dado a essas fontes de dados, e as possibilidades de análise que se perdem com o descarte dessa produção sem prévia seleção ou qualquer tratamento de preservação. Por escolas de infância compreendem-se tanto as escolas de Educação Infantil (EI) como as dos anos iniciais do Ensino Fundamental (EF), partindo-se do entendimento de que os alunos desses níveis de ensino não deixam de ser crianças e que a articulação e as políticas de transição entre as escolas de EI e EF necessitam ser repensadas continuamente.

A ideia de trabalhar com a Arqueologia das Práticas Escolares surgiu a partir da imersão nos campos de investigação científica nas escolas e da observação e do registro de inúmeras práticas escolares, as quais, ao final do ano letivo, acabavam se perdendo. E não havia sistematização e produção de um acervo do rico material de estudos e de formação de professores.

$\mathrm{Da}$ arqueologia, foram trazidos os conceitos, procedimentos e métodos de coleta de dados para se pensar as inúmeras possibilidades de constituição de acervos digitais que possibilitassem a análise da produção material do ensino na educação básica. Delimitou-se o campo de indagação às escolas de infância e estabeleceuse um profundo diálogo entre a sociologia da educação, a história, a antropologia e o pensamento pedagógico.

Como ponto de partida, procedeu-se a um levantamento bibliográfico prévio e constatou-se que, no campo da educação, não há pesquisas similares que estabeleçam um diálogo entre a arqueologia, a sociologia da educação, a história e o pensamento pedagógico, com vistas a analisar a produção da materialidade da escola.

A associação entre os campos de conhecimento história, sociologia, antropologia e arqueologia -, em constante diálogo com a pedagogia, poderá resultar no desenvolvimento de repositórios dos objetos educacionais, focados na produção material e no desenvolvimento de estratégias, práticas e ações pedagógicas que visem à divulgação do patrimônio arqueológico das escolas de infância. No Brasil, há exemplos de repositórios bemsucedidos e, dentre eles, podem-se citar o Instituto Nacional de Estudos Pedagógicos (Inep) e o Banco Internacional de Objetos Educacionais, mantido pelo Ministério da Educação (MEC).

O levantamento, a captação, a catalogação e a disponibilização dos objetos educacionais são de suma importância para dar a conhecer a cultura material da escola, entendida como a memória histórico-sociológica dos diferentes grupos que compõem as distintas experiências educacionais. E a constituição de acervos digitais dessa natureza possibilitará às comunidades escolares o direito à informação, assim como a possibilidade de conhecer e divulgar com mais dinamismo e de forma mais democrática a materialidade da escola, a fim de promover a permanente e desejável melhoria das condições objetivas de ensino, o avanço do conhecimento científico sobre a produção material da escola, bem como a formação permanente de professores.

Como campo do conhecimento privilegiado neste estudo, a arqueologia, em diálogo permanente com a sociologia da educação, com a história, com a antropologia e com o pensamento pedagógico, é a ciência capaz de contribuir para a preservação dos vestígios arqueológicos. Estes são entendidos como as marcas, os saberes e as práticas que são continuamente impressos na escola de infância e que constituem uma forma particular de conceber a educação infantil em uma dada sociedade, e as condições sociais objetivas nas quais o ensino se desenvolve nos aspectos sociais, culturais, econômicos, étnicos e religiosos.

A produção da cultura material na escola é um processo ativo pelo qual diferentes sujeitos sociais, os quais compõem uma dada comunidade escolar e que estão inseridos em determinada sociedade, interagem acerca de seu patrimônio cultural, criam e recriam a materialidade do ensino, ressignificam as normativas prescritivas impostas por organismos reguladores da educação. Nesse sentido, por meio do diálogo permanente com o cotidiano da escola, pôde-se constatar que os sujeitos da educação professores, gestores, estudantes e familiares das crianças - têm a clara compreensão do patrimônio cultural que é produzido continuamente na escola. Contudo encontram dificuldades para preservá-los, problematizá-los e produzir, a partir deles, novos conhecimentos. Nesse caminho, a universidade tem o papel central de colocar em destaque a necessidade de conservação do que denominamos a cultura material na educação da infância e, mais especificamente, os resquícios arqueológicos que se espalham pelas diferentes regiões brasileiras, de modo geral, e por Minas Gerais, em particular. 
Compreende-se que, na interlocução entre a universidade e a escola, pode ser estabelecido um processo contínuo de percepção, criação e recriação da materialidade da escola, constituindo, assim, um processo cultural dialogado. A intenção de ampliar o diálogo entre universidade e escola, na perspectiva adotada neste estudo, fundamenta-se no que Marshall (2002) denominou de "Arqueologia Comunitária", formando, entre os membros das comunidades, os gestores desse patrimônio arqueológico, a fim de constituir uma relação de mútua cooperação. Ao mesmo tempo em que permite que haja realmente a identificação desse patrimônio como herança, não como algo tão distante da realidade social e cultural dessas comunidades.

\section{ARQUEOLOGIA E A PRODUÇÃO MATERIAL DA CULTURA NA ESCOLA DA INFÂNCIA}

A cultura material engloba o estudo dos objetos materiais em sua interação com os aspectos mais concretos da vida humana e nasceu a partir de três disciplinas diferentes e complementares: a arqueologia, que pode reconstruir a história das sociedades a partir de vestígios materiais e objetos que tenham sido produzidos; a etnografia, que tem o objetivo de analisar as produções materiais inseridas nas sociedades, em diferentes momentos históricos; e a história inspirada no marxismo ${ }^{1}$. $\mathrm{O}$ estudo da cultura material tem sido, desde o início do século $\mathrm{XX}$, comprometido com as produções humanas têxteis, de cerâmicas, de mobiliários, de casas, com foco na coleta cuidadosa de objetos e num trabalho descritivo, procurando construir uma história social da tecnologia e uma história social econômica, especialmente os objetos que foram sendo estudados a fim de se capturar as práticas que não são escritas.

Também a história da cultura material se beneficiou do nascimento da sociologia, particularmente a partir dos caminhos abertos por Marcel Mauus e Henri Hubert e pelo desenvolvimento progressivo da arqueologia. Do mesmo modo, Fernand Braudel escreveu, em 1967, a obra Civilização Material e Capitalismo, a qual se tornou um marco referencial para os estudos da cultura material. Os estudos que se seguiram passaram a considerar os dados demográficos, a alimentação, a habitação, os móveis, as roupas, as produções técnicas, de modo que pudessem enfatizar que a vida era feita de massas de objetos, gestos, técnicas que absorvem pensamentos e ações de uma dada sociedade.

Dentre esses estudos, podem-se destacar os mais conhecidos no Brasil, os quais buscam revisitar certos

\footnotetext{
No ano de 1919, Vladimir Lenin cria, por meio de decreto, a Academia de História da Cultura Material da extinta União Soviética.
}

objetos ou sistemas de objetos: Roger Chartier (1998), o livro; Daniel Roche (1998), as roupas; Jean-Louis Flandrin e Massimo Montanari (1998), os alimentos; Georges Vigarello (1996), a casa, os móveis, o corpo. Tais contribuições foram fundamentais para a constituição dos estudos sobre a cultura material na escola, os quais são especialmente centrados na História da Educação, no Brasil. Compreende-se que o conjunto de fundamentos é suficiente para aumentar a síntese recente. Nesse sentido, são trazidos para esta reflexão, a fim de se ampliar o campo de indagação, tanto para a construção da história recente como para o estabelecimento de um profícuo diálogo entre a sociologia da educação e o pensamento pedagógico contemporâneo.O objetivo é ampliar as perspectivas de análise sobre a produção da materialidade da educação.

Os objetos culturais produzidos na escola oferecem um conjunto de contribuições organizadas em torno do conceito de "cultura material" (SCHIFFER, 2000). E se estáciente, no entanto, das dificuldades e dos debates que esse conceito pode suscitar. Um primeiro problema que pode ser analisado decorre da formulação ambígua e imprecisa desse conceito ao sugerir que a materialidade constitui a cultura em sua essência, quando, na realidade, abrange apenas uma das dimensões da cultura. Essa ambiguidade é ainda mais problemática se aplicada à cultura material produzida na escola da infância, mais precisamente pelo caráter difuso de seu destino final, ou ainda pelas dificuldades decorrentes de sua preservação. A fim de dirimir tal ambiguidade, uma formulação possível seria a da ideia de registro da "materialidade da cultura da escola" (OLSEN, 2003).

Essa formulação tem a vantagem de destacar que os objetos, os saberes, as falas e as performances concebidas no âmbito escolar para as crianças, ou ainda adotadas por elas, continuariam através da mídia e dos objetos dentro de circuitos culturais e sociais, técnicos e editoriais que os transportam em condição de alcance e eficácia, de nuances e modulações, sendo revelados na materialidade da cultura da escola. Destacam-se como objetos da escola: os materiais didáticos, os registros iconográficos - seja por meio dos desenhos, seja por meio de fotografias; os brinquedos, os jogos, as imagens em movimento -, os vídeos, as filmagens dos projetos pedagógicos; o mobiliário, os arranjos realizados no espaço físico. Todos esses objetos escolares são inteligíveis e consagrados na esfera histórico-sociológica, levando o discurso sobre a educação, infância, saberes e práticas docentes e discentes a se materializar.

Nesse sentido, o movimento proposto neste artigo consiste em refletir sobre uma dimensão negligenciada desses objetos: a cultural - não apenas técnica. E sobre os materiais de que esses objetos são feitos, que afetam 
a "sensibilidade", tão fortemente "persepcional", das novas gerações (MERLEAU-PONTY, 1990, 1999). Desse modo, o termo "cultura material" parece relevante para muitos historiadores e sociólogos, o que suscita o seu poder de mobilizar e reunir, em torno dos objetos de educação, especialistas de diferentes disciplinas. Portanto, esse termo é apropriado para esclarecer a gênese, para explorar alguns territórios e para mostrar as ferramentas analíticas a fim de se entender as novas formas de a escola produzir a sua materialidade.

\subsection{O tratamento dos vestígios arqueológicos}

A arqueologia, diferente de outras ciências que tratam da compreensão das sociedades, não pode observar o comportamento da população que estuda, mas pode inferir o comportamento, as ideias e os valores das pessoas a partir de materiais remanescentes do que elas fizeram e usaram e do impacto físico da sua presença no meio ambiente e social. Contribui, assim, para a sistematização da cultura material e para sua compreensão dos usos e das apropriações sociais e culturais.

$\mathrm{O}$ estudo da cultura material da escola requer a produção de meios imagéticos que permitam o registro e a preservação dos dados de pesquisa coletados. A partir dos registros desses dados, será realizada a análise iconográfica das imagens da materialidade da cultura da escola. Essa análise pode demonstrar um aprofundamento da consciência dos antepassados e contemporâneos sobre a cultura material das escolas mineiras.

Contudo, adentrar o universo da cultura material e trilhar os caminhos percorridos no presente exige determinadas condutas. Ainda para permitir ousadias, essas condutas devem cercar-se de procedimentos e de certos rigores metodológicos que garantam, ao máximo, a coerência e a observação acuradas do universo investigado. No caso deste artigo, esse universo é o da cultura material da escola, especificamente de seu olhar sobre a educação da infância. Portanto, não caberia analisar aqui a educação e a infância somente através da cultura material da escola, mas,sim, a educação e a infância que desta emergem.

Walter Benjamim (1993) evoca o confeiteiro de Barcelona, o qual, ao fabricar bonecas, colocava, em seu coração, uma bola de açúcar, apresentando o brinquedo como expressão do poder dos sentidos. Essa imagem é importante, pois nos faz refletir sobre a importância de se levar em conta as formas de produção da materialidade da cultura escolar através das imagens produzidas durante a coleta de dados para esta pesquisa.

$\mathrm{O}$ estudo das imagens, entretanto, exige ainda procedimentos próprios, não necessariamente elencados em obras que orientam a metodologia da pesquisa tradicionalmente organizada a partir de documentos escritos. Nesse sentido, o procedimento a ser utilizado na realização dos estudos sobre as imagens da cultura material da escola necessita estar fundamentado na descrição iconográfica, na sua análise e na sua interpretação. É preciso, portanto, "ver" as imagens e o que elas mostram (REIS, 2007).

Diferentemente do texto escrito - na forma ocidental -, o qual conduz o olhar em seu trajeto da esquerda para a direita, de cima para baixo, que se revela pouco a pouco, a imagem mostra-se de uma só vez, permitindo que o olhar comece a vê-la a partir de qualquer ponto e a vagueie em diferentes direções. Esse "olhar a imagem" principia um jeito diferente de compreender a imagem, suas formas, linhas, perspectivas e manchas, e é também uma das formas de pensar o que a imagem mostra, revela, expõe e relata sobre um certo imaginário, sobre uma certa representação da cultura material. Fazendo, assim, de tal maneira, que algo significativo seja revelado, é preciso que imagens e textos, representação e ideias sejam confrontados e colocados em tensão, a fim de buscar sentidos na aproximação problemática de linguagens diferentes sobre a materialidade da cultura da escola.

Desse modo, é preciso que as imagens deste estudo não se constituam em meras ilustrações do texto, nem mesmo que o texto seja o único instrumento para explicar as imagens, mas que o pesquisador (e o leitor) passeie por elas, imaginando outros significados e acrescentando questões a estas subjacentes.

As imagens da materialidade da cultura da escola constituem uma valiosa fonte de conhecimento sobre a educação, infância, saberes e práticas docentes e discentes. Assim, consideram-se essas imagens como possibilidades para um estudo da linguagem iconográfica, como uma significativa fonte de produção de conhecimento, em que a presença da cultura material é registrada não isoladamente, mas juntamente com o ambiente no qual está inserida. Pouco ainda se sabe sobre o imaginário social acerca da materialidade da cultura da escola e de sua diversidade sociocultural. O campo das imagens tem sido pouco utilizado pelos estudiosos interessados em compreender as representações da cultura material da escola, daí a importância da arqueologia da prática escolar.

\subsection{Cultura material e os bancos de objetos educacionais como suportes para a arqueologia da prática escolar na escola da infância}

O levantamento e a catalogação da cultura material da escola revelam a problemática de como gerir tal patrimônio arqueológico, o que exige análises sistemáticas, ações planejadas de médio e longo prazo e, eventualmente, uma 
mudança de percurso, além do desenvolvimento de novas estratégias de conservação dos bens produzidos pela cultura material da escola. Porém sempre resguardando a preservação da essência do material coletado, da própria cultura material e das perspectivas políticas e ideológicas a esta subjacentes. Sabe-se que, em arqueologia, pode ocorrer uma intervenção no campo de pesquisa com a coleta dos vestígios arqueológicos e, por vezes, corre-se o risco de este não mais voltar à sua estrutura original. Nesse sentido, é fundamental ter em mente a importância da preservação em dois aspectos: resguardar as informações sobre os artefatos retirados do sítio arqueológico e preservar o estado físico dos objetos que possam ser conservados por meio dos procedimentos de registro mais adequados ao material.

Evidenciou-se a necessidade de utilizar técnicas para manter esses materiais o mais próximo possível do seu estado físico original e também para preservar as informações acerca dos objetos educacionais coletados, tal como a produção de material didático específico. Como exemplo, o uso da literatura de Cordel no ensino de língua portuguesa, que se insere em esquema cultural próprio. Desse modo, a preservação e a conservação unem-se à arqueologia para juntas obterem conhecimentos sobre as práticas educativas.

O tratamento meticuloso conferido aos vestígios arqueológicos, desde o ato de coleta até sua inserção no protocolo de pesquisa, auxilia a preservação dos artefatos, como também de todas as informações possíveis relativas ao contexto político-pedagógico no qual foram produzidas. Essa nova metodologia de coleta de dados em educação é pouco conhecida no Brasil, porém apresenta possibilidades cada vez mais significativas nas análises dos sítios arqueológicos educacionais dos materiais encontrados. Assim, é necessário que se preserve o máximo de informações possíveis sobre a realidade estudada.

Desse modo, o registro das informações é essencial para a compreensão do sítio e dos materiais arqueológicos nele encontrados. Podem ser utilizados para fins de registro os cadernos de campo do coordenador e da equipe; os diários de campo dos "escavadores", isto é, dos estudiosos que farão a coleta dos vestígios arqueológicos educacionais; a fotografia; o videodocumentário; o escaneamento de documentos impressos; e o desenho de todas as peças "escavadas", caso não seja possível realizar o registro fotográfico e/ou videográfico, o escaneamento, entre outros procedimentos.

O registro fotográfico é procedimento efetuado em praticamente todos os materiais coletados no campo de pesquisa. Os vestígios arqueológicos são fotografados para fins de seu reconhecimento no sistema digital de documentação e identificação, quando da procura destes no acervo. Depois de todas as etapas anteriores concluídas, as informações geradas são inseridas no protocolo de registro e disponibilizadas em banco de dados, os quais são criados para registrar os dados referentes aos sítios arqueológicos, incluindo os dados descritivos e imagéticos. Para tanto, é necessária a criação de um formulário eletrônico com as informações sobre os dados espaciais e materiais descritivos dos artefatos catalogados no mesmo contexto arqueológico do sítio; uma base de dados relativa à entrada desses artefatos na coleção; e, finalmente, um registro inserido em cada protocolo com as informações físicas de cada objeto individualmente. Esse conjunto articulado de procedimentos produzirá dados que serão gerados em núcleos ou grupos de estudos em arqueologia da prática escolar e disponibilizados em repositórios de informações educacionais.

A organização do material de pesquisa e de formação de professores decorrente da coleta arqueológica dos dados necessita ser disponibilizada em repositórios de informações educacionais abertos e gratuitos. E a ideia é facilitar o compartilhamento de conhecimentos e experiências bem-sucedidas em educação, bem como oferecer aos ingressantes na carreira docente a visibilidade da produção material da escola. Na mesma direção, as investigações acadêmicas podem ser enriquecidas com um farto material que dê mais força de expressão ao que ocorre nas escolas, possibilitando análises mais complexas de seu cotidiano.

Os bancos de objetos educacionais são Repositórios Digitais (RDs) constituídos por bases de dados on-line, os quais reúnem, de maneira organizada, a produção científica de uma instituição ou área temática e armazenam arquivos de diversos formatos, o que facilita a inserção de arquivos, vídeos, documentários, fotografias, animações, músicas, entre outros. Esses modos de armazenamento resultam em uma série de benefícios, tanto para os pesquisadores quanto para as instituições ou sociedades científicas, uma vez que proporcionam maior visibilidade dos resultados de estudos e possibilitam a preservação da memória científica institucional universitária e escolar.

RDs podem ser institucionais ou temáticos, ou ainda ambas as combinações, permitindo uma multiplicidade de experiências. Os repositórios institucionais lidam com a produção científica de uma determinada instituição. Já os repositórios temáticos lidam com a produção científica de uma determinada área, sem limites institucionais.

\section{ETNOARQUEOLOGIA E PRODUÇÃo MATERIAL DA CULTURA NA ESCOLA DA INFÂNCIA}

Funari et al. (1999) ressaltam que a arqueologia é um campo do conhecimento científico identificado com 
diferentes disciplinas, como a antropologia, a história, a sociologia e a pedagogia. Desse modo, a arqueologia é a ciência que procura recuperar e colocar em evidência o patrimônio arqueológico movido pela identidade cultural de populações atuais. Compreende-se, desse modo, que seu cerne se situa no diálogo, profundo e contínuo, com os diferentes campos disciplinares, bem como no conhecimento empírico da cultura material de diferentes grupos sociais. As fontes orais, os depoimentos informais e os vestígios arqueológicos são o ponto de partida para o desenvolvimento dos estudos da arqueologia.

A cultura material é, portanto, o objeto próprio da arqueologia e o testemunho da sociedade. No caso da cultura material da escola da infância, os resquícios arqueológicos têm tido destino difuso e, em muitos casos, são descartados, indicando, nesse sentido, que parte significativa da materialidade da cultura escolar é conhecimento que se perde. A trajetória recente da arqueologia expressase em diferentes contextos da produção material. Há a indagação, entre os arqueólogos, sobre qual é a relação do trabalho arqueológico na sociedade contemporânea e o que esta espera, exige e anseia da arqueologia e quais conhecimentos pode produzir sobre o passado recente e sobre o presente do campo pesquisado.

Segundo Funari et al. (1999, p. 4), a arqueologia constrói ou desconstrói um individualismo capitalista: "[...] na cultura material cotidiana de capitalistas ou de trabalhadores, à porcelana de aparato se opõe a cerâmica dos operários, a grande arquitetura erudita à construção vernacular".

Kramer (1979) afirma que a arqueologia combinada com os procedimentos da etnografia vem sendo pensada como uma especialidade que estuda as sociedades contemporâneas no sentido de elaborar hipóteses, conceber modelos interpretativos e desenvolver teorias novas sobre a relação entre as pessoas e sobre a produção da materialidade, ao que a autora denomina de "etnoarqueologia". Tal combinação surgiu da necessidade prática da arqueologia de utilizar o dado etnográfico para fundamentar suas interpretações sobre os contextos arqueológicos, as quais vêm sendo desenvolvidas no âmbito dos debates sobre o modo como tais interpretações sobre a cultura material podem ser conduzidas. Do mesmo modo, a etnoarqueologia auxilia no refinamento dos procedimentos de obtenção de dados etnográficos pelos próprios arqueólogos, ampliando os temas de pesquisa e estabelecendo o diálogo interdisciplinar com outros campos do conhecimento.

\section{À GUISA DE CONCLUSÃo}

O estabelecimento de uma arqueologia da prática escolar por meio da produção da materialidade da cultura das escolas tem como propósito apresentar novos argumentos, olhares e hipóteses que possam ampliar a maneira como a produção material da escola é interpretada, colaborando para uma melhor compreensão de toda a gama de relações e práticas sociais, culturais, formativas, econômicas e simbólicas que caracterizam o universo escolar.

Como fonte de inspiração para a formulação de novas hipóteses a respeito da organização e da cultura material produzida pelas escolas, muitas das reflexões surgiram de um intenso diálogo com as ciências sociais - em especial a história, a sociologia, a antropologia -, as quais estão em constante diálogo com a pedagogia. A partir de referenciais etnográficos, na prática, o olhar antropológico traz consigo a possibilidade de reinterpretações da própria cultura material das escolas. Por meio da inserção dos procedimentos e das técnicas arqueológicas, é possível obter uma importante contribuição para a realização de análises ainda não exploradas no campo da educação e da cultura. Assim, a combinação de metodologias poderá tornar possível a conservação do patrimônio arqueológico pertencente às escolas, o que requer recursos financeiros e condições adequadas de produção de acervo e sua disponibilização à comunidade escolar e acadêmica. Ressalta-se, ainda, a necessidade de manter a integridade dos objetos educacionais e a preservação das informações sobre estes, pois, uma vez inseridos em acervos digitais, precisam passar por procedimentos de curadoria periodicamente.

Assim, há uma multiplicidade de possibilidades de desenvolvimento de estudos e pesquisas capazes de produzir novos e complexos conhecimentos sobre a realidade escolar, sobre o seu cotidiano e, sobretudo, sobre os modos como a escola produz sua materialidade. Paralelamente a todos os diferenciais investidos numa arqueologia da prática escolar, é fundamental direcionar uma ação conscientizadora aos pesquisadores, como uma "alfabetização patrimonial", no sentido de ressaltar a relevância de práticas que promovam a conservação e preservação dos artefatos a serem estudados por eles próprios.

A arqueologia possibilita estudar uma grande variedade de objetos e vestígios e propor conclusões sobre os aspectos não materiais da cultura. Os meandros dessas descobertas têm aumentado nas últimas décadas, porém uma atenção sempre limitada tem sido dada ao que o registro arqueológico pode dizer sobre a transferência de conhecimento cultural através das práticas pedagógicas e sobre a consequente aprendizagem que esta pode proporcionar.

As reflexões apresentadas neste artigo convidam a pensar que a arqueologia pode beneficiar muito a preservação da cultura material da escola com a 
compreensão das dimensões sociais de transferência de conhecimento. Do mesmo modo, ao se ter em mente os aspectos da materialidade das escolas, é possível enriquecer a compreensão da relação entre os vestígios de materiais e as perspectivas formadoras das novas gerações.

Diante das análises apresentadas, muitas questões são suscitadas. A cultura material altera, influencia, condiciona as aprendizagens? Quais seus impactos nos modos como se aprende, ou como se ensina, sendo-se mediado pela produção da materialidade da escola? Como e por quais meios as pessoas aprendem em diferentes cenários sociais? Quem está ensinando? Por que estudantes estão aprendendo, ou não? Quais são os resultados dessa aprendizagem? Como se reconhece a transferência de conhecimento no registro arqueológico? Essas perguntas são fundamentais para a compreensão da cultura material da escola, particularmente as relacionadas com a transmissão e com as tradições de aprendizagem e de educação de todo o universo cultural de cada sociedade.

Dessa maneira, conclui-se este artigo com a proposição de ações acadêmicas e de políticas que de fato propiciem a visibilidade do patrimônio arqueológico das escolas com a participação das comunidades científica e escolar - estudantes, profissionais do ensino, famílias das crianças, gestores das escolas.

\section{REFERÊNCIAS}

BANCO INTERNACIONAL DE OBJETOS EDUCACIONAIS: UM RELATO DE EXPERIÊNCIA DO PROJETO ODIN. Revista ACB: Biblioteconomia em Santa Catarina, Florianópolis, v. 17, n. 1, p. 174-193, jan./jun. 2012.

BAUDRILLARD, Jean. O sistema dos objetos. 4. ed., 3a reimpressão. Tradução de Zulmira Ribeiro Tavares. São Paulo: Perspectiva, 2006.

BAUER, Martin W.; GASKELL, G. (Org.). Pesquisa qualitativa com texto, imagem e som. Um manual prático. Petrópolis, RJ: Vozes, 2002.

BEAUD, Stephan; WEBER, Florence. Guia da pesquisa de campo. Produzir e analisar dados etnográficos. Petrópolis: Vozes, 2007.

BENCOSTA, Marcus Levy (Org.). Culturas escolares, saberes e práticas educativas: itinerários históricos. São Paulo: Cortez, 2007.

BENJAMIN, Walter. Obras escolhidas: magia e técnica, arte e política. São Paulo: Brasiliense, 1993.

BICUDO, Maria Aparecida Viggiani; ESPÓSITO, Vitória Helena Cunha. Pesquisa qualitativa em educação. Piracicaba: Editora Unimep, 1997.

BINOTTO, Sibila F. T.; BASSO, Marcus V. A. Banco Internacional de Objetos Educacionais: um relato de experiência do Projeto ODIN. Revista ACB: Biblioteconomia em Santa Catarina, v. 17, n. 1, jan./jul. 2012.
BITTENCOURT, José Neves. Armas, beleza, computadores: a cultura material em algumas observações introdutórias. Bol. Mus. Para. Emílio Goeldi. Ciênc. hum. [on-line], v. 6, n. 1,p. 25-39, 2011 [citado 2014-10-22]. Disponível em: $<\mathrm{http}: / /$ www.scielo.br/scielo.php?script $=$ sci_arttext\&pid $=\mathrm{S} 1981$ $81222011000100003 \& \operatorname{lng}=p$ t\&nrm $=\mathrm{iso}>$. Acesso em: 10 nov. 2014. ISSN 1981-8122. http://dx.doi.org/10.1590/S198181222011000100003

BOGDAN, Robert C. Investigação qualitativa em educação: uma introdução à teoria e aos métodos. Porto: Porto Editora, 1994.

BRAUDEL, Fernand. Civilização material e capitalismo. São Paulo: Cosmos, 1967.

CARVALHO, Marília Pinto de; VILELA, Rita Amélia Teixeira; ZAGO, Nadir (Org.). Itinerários de pesquisa: perspectivas qualitativas em Sociologia da Educação. Rio de Janeiro: DP\&A, 2003 .

CHARTIER, Roger. A aventura do livro: do leitor ao navegador. São Paulo: Editora da UNESP, 1998.

CORBIN, Juliet; STRAUSS, Anselm. Basics of qualitative research: tecniques and procedures for developing grounded theory. 2. ed. Thousand Oaks, London e New Delhi: Sage, 1998.

COSTA, Marisa Vorraber (Org.). Caminhos investigativos: novos olhares na pesquisa em educação. 2. ed. Rio de Janeiro: DP\&A, 2002

COSTA, Marisa Vorraber (Org.). Caminhos investigativos II: outros modos de pensar e fazer pesquisa em educação. 2. ed. Rio de Janeiro: DP\&A, 2002a.

DENZIN, Norman K. Handbook of qualitative research. Thousand Oaks: Sage, 2000.

DEPPERMANN, Arnulf. Gespräche analysieren. Eine Einführung. Opladen: Leske+Budrich, 2001.

FLICK, Uwe. Dados visuais para pesquisa qualitativa. Porto Alegre: Bookman/Artmed, 2009.

FLICK, Uwe. Desenho na pesquisa qualitativa. Porto Alegre: Bookman/Artmed, 2009

FOUCAULT, Michel. Microfísica do poder. Rio de Janeiro: Edições Grall, 1979.

FOUCAULT, Michel. A arqueologia do saber. Rio de Janeiro: Forense Universitária, 2009.

FUNARI, P. P. A.; HALL, M.; JONES, S. (Ed.). Historical archaeology, back from the edge. Londres, Routledge, 1999.

GHIGLIONE, Rodolphe; MATALON, Benjamin. O inquérito. Teoria e prática. Oeiras: Celta Editora, 1997.

HÉBRARD, Jean. Por uma bibliografia material das escritas ordinárias: o espaço gráfico do caderno escolar (França - séculos XIX e XX). Revista Brasileira de História da Educação RBHE, n. 1, p. 115-142, jan./jun. 2001.

KRAMER, Carol (Ed.). Ethnoarchaeology: implications of ethnography for archaeology. New York: Columbia University Press, 1979. p. 277-287.

LE GOFF, Jacques. História e memória. 6. ed. Campinas, São Paulo: Editora da Unicamp, 2012.

LIMA, Tania Andrade. Cultura material: a dimensão concreta das relações sociais. Bol. Mus. Para. Emílio Goeldi. Ciênc. 
hum. [on-line]. v. 6, n. 1, p. 11-23, 2011 [citado 2014-10-22]. Disponível em: <http://www.scielo.br/scielo.php?script=sci arttext\&pid $=\mathrm{S} 1981-81222011000100002 \& \operatorname{lng}=\mathrm{pt} \& \mathrm{nrm}=\overline{\mathrm{i}}$ so>. Acesso em: 21 dez. 2014. ISSN 1981-8122. http://dx.doi. org/10.1590/S1981-81222011000100002

MARSHALL, Y. What is community archaeology? World Archaeology, 32 (02), p. 211-219, 2002. http://dx.doi. org/10.1080/0043824022000007062

MAUSS, Marcel. Sociologia e antropologia. São Paulo: Cosac \& Naify, 2003.

MAUSS, Marcel; HUBERT, Henri. Sobre o sacrifício. São Paulo: Cosac \& Naify, 2005.

MERLEAU-PONTY, Maurice. O primado da percepção e suas consequências filosóficas. Campinas, SP, 1990.

MERLEAU-PONTY, Maurice. Fenomenologia da percepção. São Paulo: Martins Fontes, 1999.

OLSEN, Bjørnar. Material culture after text: re-membering things. Norwegian Archaeological Review, v. 36, n. 2, p. 87-104, 2003. http://dx.doi.org/10.1080/00293650310000650

PATRÍCIO, Ângela. Notas sobre o mobiliário escolar em Portugal no século XX. Lisboa, 2006. Disponível em: $<$ http:// www.educ.fc.ul.pt/docentes/opombo/hfe/lugares/mobiliario/ hfe.htm>. Acesso em: 08 out. 2014.

REIS, Magali. À imagem e semelhança: um estudo sobre a criança na pintura de Eliseu Visconti, Vicente do Rego
Monteiro, Tarsila do Amaral e Lasar Segal. (Tese de Doutorado) - Faculdade de Educação, UNICAMP, 2007.

ROCHE, Daniel. História das coisas banais. Tradução de Telma Costa. Lisboa: Editorial Teorema, 1998.

SCHIFFER, Michael Brian. Social theory in archaeology. Building bridges. In: SCHIFFER, M. B. (ed.). Social theory in archaeology. Salt Lake City: The University of Utah Press, 2000. p. 1-13.

TAROT, Camile. Marcel Mauss et l'invention du symbolique. La Revue du MAUSS, semestrielle: Plus réel que le réel, le symbolisme, n. 12, 1998.

TRIGER, Bruce G. História do pensamento arqueológico. São Paulo: Odysseus, 2004.

VIGARELLO, Georges. O limpo e o sujo, uma história da higiene corporal. São Paulo: Martins Fontes, 1996.

WENDRICH, Wileke (Org.). Archaeology and apprenticeship: body knowledge, identity, and communities of practice. Arizona, EUA: The University of Arizona Press, 2013.

WUCHTERL, Kurt. Methoden der gegenwartsphilosophie. Rationalitätskonzepte im Widerstreit. Bern, Stuttgart, Wien: Haupt, 1999.

Submetido em: 15/03/2015 Aprovado em: 17/02/2016 